Provided for non-commercial research and education use. Not for reproduction, distribution or commercial use.

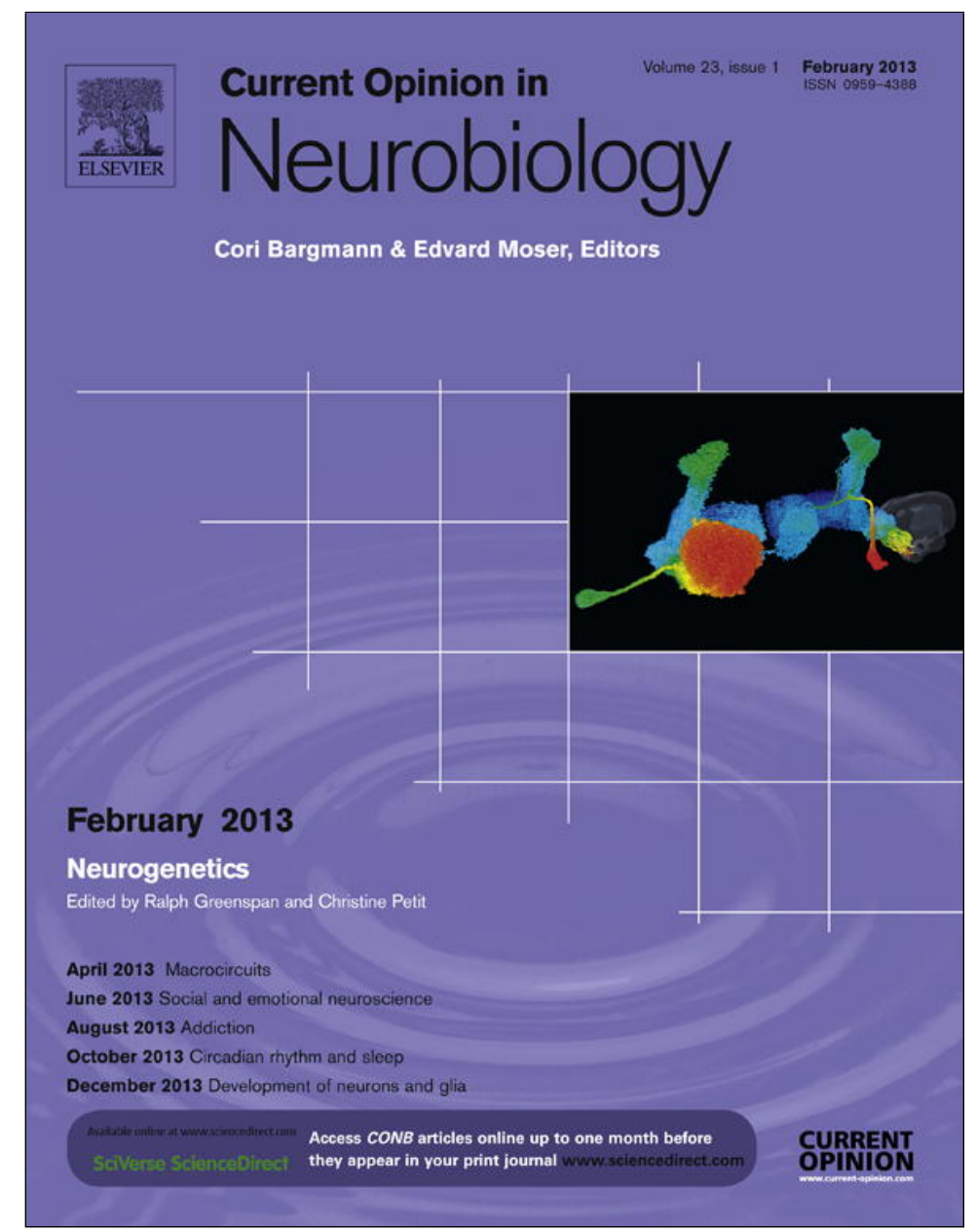

This article appeared in a journal published by Elsevier. The attached copy is furnished to the author for internal non-commercial research and education use, including for instruction at the authors institution and sharing with colleagues.

Other uses, including reproduction and distribution, or selling or licensing copies, or posting to personal, institutional or third party websites are prohibited.

In most cases authors are permitted to post their version of the article (e.g. in Word or Tex form) to their personal website or institutional repository. Authors requiring further information regarding Elsevier's archiving and manuscript policies are encouraged to visit:

http://www.elsevier.com/copyright 


\section{The molecular basis of social behavior: models, methods and advances}

Adria C LeBoeuf ${ }^{1,2}$, Richard Benton ${ }^{1}$ and Laurent Keller ${ }^{2}$

\begin{abstract}
Elucidating the molecular and neural basis of complex social behaviors such as communal living, division of labor and warfare requires model organisms that exhibit these multifaceted behavioral phenotypes. Social insects, such as ants, bees, wasps and termites, are attractive models to address this problem, with rich ecological and ethological foundations. However, their atypical systems of reproduction have hindered application of classical genetic approaches. In this review, we discuss how recent advances in social insect genomics, transcriptomics, and functional manipulations have enhanced our ability to observe and perturb gene expression, physiology and behavior in these species. Such developments begin to provide an integrated view of the molecular and cellular underpinnings of complex social behavior.
\end{abstract}

\begin{abstract}
Addresses
${ }^{1}$ Center for Integrative Genomics, Faculty of Biology and Medicine, University of Lausanne, $\mathrm{CH}-1015$ Lausanne, Switzerland

${ }^{2}$ Department of Ecology and Evolution, Faculty of Biology and Medicine,
\end{abstract} University of Lausanne, $\mathrm{CH}-1015$ Lausanne, Switzerland

Corresponding authors: Benton, Richard (Richard.Benton@unil.ch) and Keller, Laurent (Laurent.Keller@unil.ch)

\section{Current Opinion in Neurobiology 2013, 23:3-10 \\ This review comes from a themed issue on Neurogenetics \\ Edited by Ralph Greenspan and Christine Petit \\ For a complete overview see the Issue and the Editorial \\ Available online 17th September 2012 \\ 0959-4388/\$ - see front matter, (C) 2012 Elsevier Ltd. All rights reserved. \\ http://dx.doi.org/10.1016/j.conb.2012.08.008}

\section{Introduction}

Social behavior encompasses a diversity of interactions between members of the same species, including courtship, aggression, aggregation and migration. Genetically accessible model organisms, such as Drosophila, C. elegans and mice, have been used to study the molecular basis of social behaviors such as courtship and aggression [1,2]. However, several social animals, including humans, exhibit more sophisticated interactions and establish hierarchical societies in which individuals assume specific responsibilities that contribute to the success of the group. The molecular, neuronal and physiological mechanisms by which such social structures are established are poorly understood.

Social insects have been valuable models to understand the behaviors of complex animal societies, principally from ethological and ecological perspectives. Unfortunately, the long generation time of most social insect species and the difficulty of controlled breeding in the laboratory (Table 1) have prevented classical genetic analyses of their behaviors. Progress in social insect genomics and transcriptomics, as well as gene manipulation technologies such as RNA interference (RNAi), now offer opportunities to use these insects to study how genetic and environmental contributions interact to control societal organization.

In this review, we first present a primer on social insects, and then discuss how methodological advances drawn from a range of recent observational and functional studies have increased our understanding of social insect behavior.

\section{A primer on social insects}

The major organizing principle of ant, bee, wasp and termite societies is reproductive division of labor: one or a few queens specialize in reproduction while the workers (which are all females in ants, bees and wasps) participate in co-operative tasks such as building the nest, collecting food, rearing the young and defending the colony (Figure 1 and Table 1). While there is tremendous variation in many aspects of social biology ([3]; Table 1 ), a central issue is to understand the process of caste determination, whereby genetically identical individuals develop into queens or workers, and if the latter, what type of worker. Caste determination was assumed to depend on environmental factors (e.g. nutrition, pheromone exposure, temperature), but increasing evidence exists for genetic factors affecting this process in several species $\left[4,5^{\circ}, 6\right]$. Worker castes, such as 'nurse' and 'forager,' are not fixed, however, as individuals can change their behavioral states over the course of their lives (agerelated behavioral maturation, or polyethism) $[7,8]$.

Early investigations of social insect physiology characterized the relationship between caste determination and hormone levels. For example, in ants, high levels of juvenile hormone $(\mathrm{JH})$ in a larva correlate with its development as a queen $[9,10]$, as well as differentiation as a major worker in species with distinct morphological worker castes (Figure 2) $\left[11^{\bullet}, 12,13\right]$. In honeybees and ants, increasing JH level (naturally, or with JH analogs) causes individuals to cease brood care, leave the nest, and begin foraging (Figure 2) [14-17]. What induces these endocrine changes and how they exert their effects are largely unknown. 


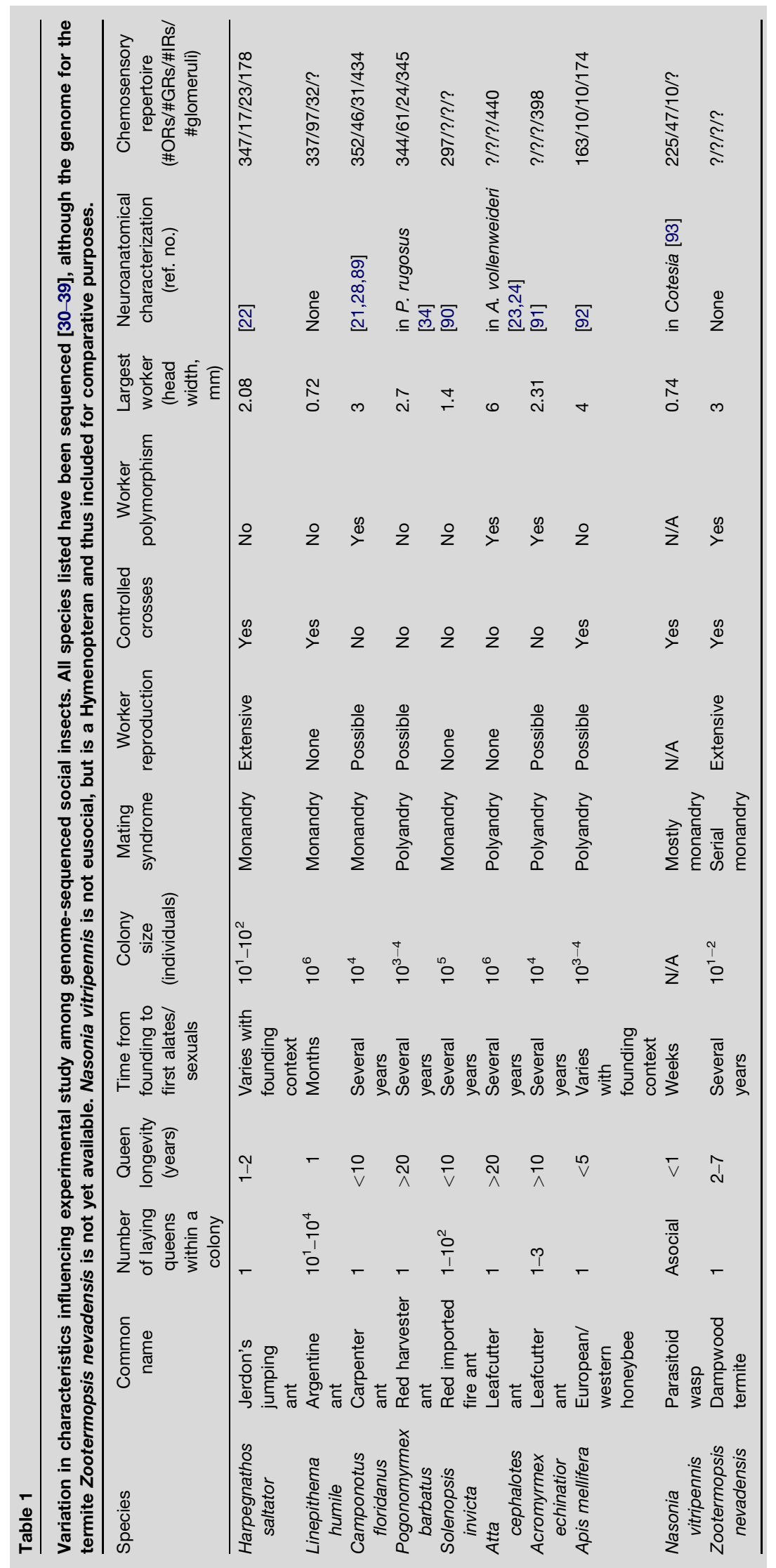




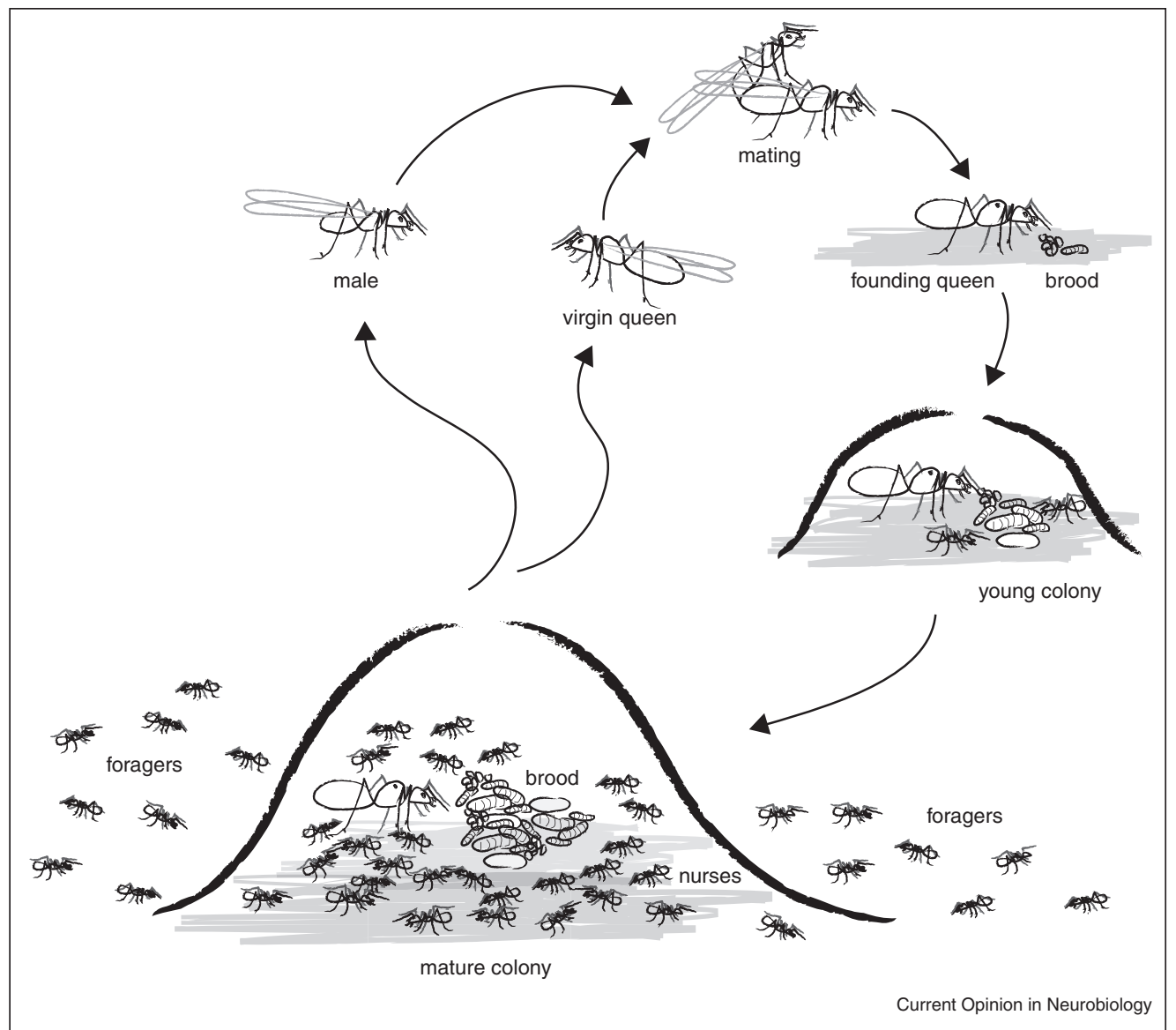

Schematic of a 'typical' life cycle of a social insect colony. After mating (top), a founding queen chooses a suitable site for the nest and begins laying eggs, which she nourishes from her own body reserves. These eggs will produce the first workers who differ significantly in morphology, physiology and lifespan from the queen, and who assist the development of the young colony by foraging and tending to new eggs, larvae and pupae. Over months or years, the number of workers in the colony increases, and eventually the founding queen begins to produce new queens and males. These reproductive individuals fly out of their respective colonies in a co-ordinated manner to mate. Many species-specific variations on this cycle exist: for example, in social Hymenoptera (ants, bees, wasps), males die shortly after mating, while in termites the male and female reproductives found the colony together as king and queen.

\section{Physiological and molecular correlations of social insect behavior}

How members of a colony co-ordinate their behavior has been addressed by neurochemical, neuroanatomical and - more recently - molecular approaches. Physiological and anatomical studies have focused on detection of pheromones and other environmental chemicals. Visualization of odor-evoked neuronal activation and plasticity in insect brains was pioneered in the honeybee, favored by its relatively large head (Table 1) [18-20]. The neurophysiology and anatomy of the ant olfactory circuits are also beginning to be explored [21-28]. Comparisons of the olfactory pathways between different castes of ants and honeybees have provided some information on how representation of the same stimulus may differ between colony members $[24,25,29]$. However, understanding the functional significance of these distinctions will require more specific knowledge of the pheromone signals, the receptors that recognize them, as well as technical innovations to precisely manipulate the functions of the neural circuits.

In the last few years, the molecular basis of social organization has begun to be deciphered through comparative genomics made possible by the sequencing of one bee, three wasp and seven ant species [30-39]. Exploitation of this wealth of information has only just started, but some interesting features are already appearing. For example, all annotated ant, bee and wasp species have several-fold more odorant receptors than most solitary insects (Table 1), suggesting that enhanced olfactory abilities may contribute to complex social organization. 


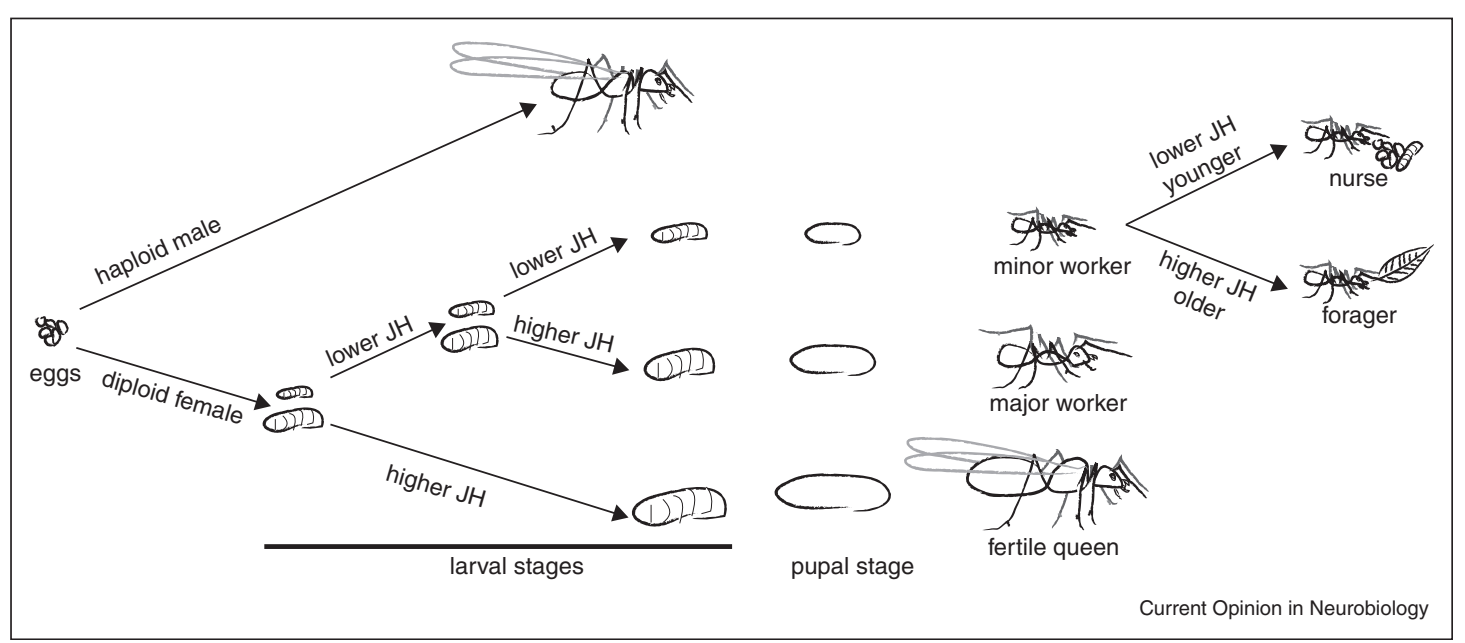

Morphological and behavioral development in social Hymenoptera. Sex is determined through ploidy level. Among the diploid females, queen versus worker fate is affected mostly by environmental factors, and appears to be related to juvenile hormone (JH) levels: the larvae that develop into queens typically have higher $\mathrm{JH}$ titers than worker larvae. In species with distinct morphological worker castes, larvae of major workers also have more $\mathrm{JH}$ than larvae of minor workers. Most social Hymenoptera also exhibit age-related polyethism, where young workers with low $\mathrm{JH}$ levels engage in brood care as nurses but as they age the titers of $\mathrm{JH}$ increase and there is a transition to foraging behavior.

Gene expression profiling in social insect brains has revealed that differences in behavior among workers from the same colony are associated with widespread (several 1000) gene expression differences $\left[40,41,42^{\bullet}, 43-46\right]$. Most of this work has been conducted in honeybees, where microarrays have been used to identify genes differentially expressed between nurses and foragers, and between inbred honeybees lines that differ in their aggressiveness. The most robustly differentially expressed genes in nurses and foragers are part of lipid and sugar biosynthesis and degradation pathways. This observation is consistent with both the changing sugar and lipid levels measured during the maturation of nurses to foragers $\left[47^{\bullet}, 48,49\right]$, and the close relationship between $\mathrm{JH}$ and metabolism in other insects $[50,51]$.

One global finding of these expression experiments was the existence of transcriptional regulatory network modules (i.e. groups of co-regulated genes controlled by similar transcription factors) associated with matu-

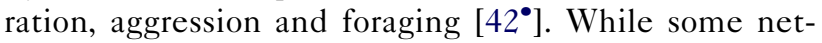
work modules are unique to social insects, others show high overlap with known Drosophila transcriptional networks. For example, aggressive behavior in both bees and fruitflies appears to be controlled by the same transcription factor network, spearheaded by the gene Deaf1 [45]. Intriguingly, a second network controlled by Ultraspiracle - one of the nuclear receptors for $\mathrm{JH}$ (and other insect hormones) that regulates larva-adult transitions in Drosophila - also controls behavioral maturation and foraging in honeybees. This finding provides an example of co-option of an ancestral insect developmental pathway for modulation of behavior changes in social insects [52].

There is little information on the mechanisms underlying differences in gene expression among castes and behavioral groups. Epigenetic modifications are attractive candidates as these could be directly modulated by environmental factors, such as nutrition or stress $[53,54]$. An analysis of the distribution of methyl cytosines (a well-known epigenetic mark) in the brains of honeybee queens and workers using shotgun bisulfite sequencing revealed that most methylation occurs in highly conserved genes [55]. Approximately $10 \%$ of these genes were differentially methylated between queens and workers, indicating that this DNA modification may be an important mechanism of caste determination. Closer examination of the distribution of methyl cytosines within the differentially methylated genes revealed a concentration around alternatively spliced exons, hinting that this epigenetic mark influences expression of castespecific transcripts. Similar observations were made in the methylomes of several ant species [56,57]. One study also identified cases of monoallelic methylation associated with allele-specific expression [56]. Some of these cases were caste-specific, hinting at the possibility of parental or caste-specific imprinting as a mechanism to specify caste identity.

\section{Perturbations of social insect physiology and behavior}

Although precise genetic manipulations are not yet feasible in social insects, several other types of experimental 
perturbation have been employed. An initial approach was to ask how a colony reacts to societal disruption. For example, when all foragers are removed from an ant or bee colony, there is a rapid behavioral shift, with previously specialized nurses beginning to forage [15]. Despite important age and genetic influences on an individual's behavior, such experiments reveal significant flexibility at the level of the colony, with individuals assuming tasks that are in greater demand. Importantly, the shift to foraging is accompanied by an increase in $\mathrm{JH}$ titer $[14,58]$ and changes in brain gene expression levels toward patterns typical of foragers [40].

Given the numerous correlations between hormone levels and caste determination among groups of workers, pharmacological manipulation of hormones or their signaling pathways has been a logical and fruitful avenue to test causality between endocrine function and worker development and behavior. The molecule most used is a JH analog, methoprene [59]. When applied to ant or bee larvae, methoprene treatment promotes queen and/or major worker developmental fate, depending on the time of application [9,10,13]. Methoprene treatment of adult honeybee workers also induces a transition to foraging [8], and brain structural changes typically associated with behavioral maturation [60]. Methoprene was also used to demonstrate that $\mathrm{JH}$ increases both fertility and the likelihood of a transition to foraging behavior in the primitively eusocial Polistes wasp [61 $\left.{ }^{\circ}\right]$.

Another avenue to study the regulation of behavior in colonies is to appropriate the pheromones involved in colony communication. In the termite Reticulitermes speratus, queens produce a pheromone that inhibits the differentiation of new fertile females. This pheromone is predominantly composed of two chemicals, n-butyl-nbutyrate and 2-methyl-1-butanol [62 $2^{\circ}$. Synthetic versions of these molecules are sufficient to inhibit queen differentiation $\left[62^{\bullet}, 63\right]$. Surprisingly, the same two volatiles are also emitted by eggs and can attract sterile workers. How this termite pheromone acts both to suppress fertility recruitment and to control worker recruitment remains to be determined. However, genomic resources in other species, notably the honeybee, have facilitated identification of the receptors and downstream cellular/molecular targets for their particular pheromone cues [44,64], and sequencing of the termite genome should offer similar access.

To perturb gene function directly, RNAi has emerged as a powerful technology. Typically, double-stranded RNA (dsRNA) corresponding to the gene of interest is either injected into the adult abdomen or fed to the entire colony $[65,66]$. In many insects, dsRNA persists over time and over developmental transitions, indicating that it functions systemically [67,68]. However, the efficiency of RNAi is gene-specific, tissue-specific and species-specific, requiring careful validation controls. RNAi has been employed in bees $\left[47^{\bullet}, 65,69-71\right]$, wasps [72], ants [73] and termites $\left[66,74^{\bullet \bullet}, 75\right]$. One recent study in honeybees used single and combined RNAi against JH esterase (which degrades JH), Vitellogenin (an endocrine factor that antagonizes $\mathrm{JH}$ action) and/or the putative $\mathrm{JH}$ receptor Ultraspiracle to show how JH and Vitellogenin levels may co-ordinately modulate gustatory sensitivity and metabolism underlying changes in food preferences $\left[47^{\bullet}\right]$.

Many genes implicated in social behavior are not genetic novelties of social species but have been co-opted from ancestral pathways also present in solitary insects (e.g. Ultraspiracle, described above). Thus, studies in other model systems provide useful information to understand the biology of social insects. For example, scouting behavior in honeybees - in which individuals seek novel food sources or nest sites - is controlled by conserved neurotransmitter systems (e.g. catecholamines) that are implicated in similar 'novelty-seeking' behavior in $C$. elegans and humans $[41,76]$. Beyond such general homologies, experimentally tractable model systems can be employed to characterize the function of particular molecules. This approach is illustrated by a study of royalactin, the protein in royal jelly responsible for the development of honeybee larvae into queens $\left[77^{\bullet \bullet}\right]$. Remarkably, feeding of royalactin to Drosophila melanogaster larvae induced their development into adults with several 'queen-like' characteristics: larger size, more rapid development, and increased fertility. Harnessing the genetic knowledge and tools in the fruit fly, royalactin was shown to exert these effects through activation of Epidermal Growth Factor Receptor (EGFR) signaling in the fat body, with evidence that EGFR influences body size through the p70 S6 kinase, developmental rate through the Mitogen Activated Protein Kinase and ovary development by increasing JH levels. Importantly, the relevance of these findings was confirmed by RNAi of homologous honeybee genes. Whether 'queen-like' Drosophila also displays altered behavior as a result of rich nourishment remains an intriguing question.

\section{Conclusions and perspectives}

Molecular approaches are revolutionizing our understanding of the biology of social insects, permitting both observation and testing of causal relationships between genes, environmental influences and behavior. We close by considering three priorities for experimental development to allow further advances in our understanding of social behavior in these organisms.

The first is in vivo manipulation of gene function. While RNAi is proving useful, it is limited in spatial and temporal resolution. Heritable transgenic manipulation of social insects with Zinc-Finger Nucleases or TALENs $[78,79]$ remains a distant goal, but short-term, tissuespecific transgenic manipulation using viral vectors may 
be possible [80]. Initial progress in introducing exogenous DNA elements into neurons using baculoviruses has been reported in the honeybee [81]. Once the (significant) hurdle of efficient and selective in vivo DNA transformation is overcome, the experimental potential for anatomical tracing, physiological recording, gene inhibition and misexpression is enormous.

Second, the relative ease of genome sequencing should be further exploited for both cross-species comparisons and finer-scale analyses. One interesting application will be to identify the genetic basis of natural social polymorphisms. An excellent candidate for study exists in the fire ant, Solenopsis invicta, where a single Mendelianinherited locus controls whether a colony will tolerate one queen or multiple queens [82,83]. We note that important behavioral genetic insights in Drosophila and C. elegans have come from identification of loci underlying natural behavioral polymorphisms $[84,85]$.

Finally, our ability to explain and manipulate social behavior will only be as good as our ability to observe and measure it. High-resolution, quantitative analysis of behavior in social insect colonies will be necessary, and this requires the recognition of distinct individuals. Automated tracking systems developed for Drosophila [86] are not practical for social insects because workers live in too high densities and frequently walk on top of each other, resulting in mixed identities. Radio-frequency identification systems have been used to recognize individual ants and wasps passing at given locations $[87,88]$. While it is useful to study who is foraging in a colony or whether individuals visit foreign nests, such systems do not permit study of an individual's behavior or infer who is interacting with whom in a nest. A new system based on fiducial identification labels that allow automated video-tracking of all the individuals in a colony over long periods of time has been developed (D. Mersch, A. Crespi and L. Keller, unpublished). This system may allow characterization of individual and group behaviors of social insects reared in two-dimensional nests, such as ants. The possibility to combine precise quantitative behavioral data with social, pharmacological and gene expression manipulations promises to reveal previously unattainable insights into the molecular and cellular basis of social insect behavior.

\section{Note added in proof}

After this review was accepted, a comprehensive phylogenetic and expression analysis of chemosensory receptors in two ant species was published [94].

\section{Acknowledgements}

We thank Mischa Dijkstra, Sophie Martin, Pavan Ramdya, Gene Robinson, Ana Silbering and Simon Sprecher for comments on the manuscript. Research in R.B.'s laboratory is supported by the University of Lausanne, an ERC Starting Independent Grant and the Swiss National Science Foundation. Research in L.K.'s laboratory is supported by the University of Lausanne, an ERC Advanced Grant and the Swiss National Science Foundation.

\section{References and recommended reading}

Papers of particular interest, published within the period of review, have been highlighted as:

- of special interest

-. of outstanding interest

1. Levine JD, Billeter J-C: Who is he and what is he to you? Recognition in Drosophila melanogaster. Curr Op Neuro, in press.

2. Vosshall LB: Into the mind of a fly. Nature 2007, 450:193-200.

3. Hölldobler B, Wilson EO: The Superorganism: The Beauty, Elegance, and Strangeness of Insect Societies. New York: W.W. Norton; 2009.

4. Crozier $\mathrm{R}$, Schlüns $\mathrm{H}$ : Genetic caste determination in termites: out of the shade but not from Mars. Bioessays 2008, 30:299-601.

5. Libbrecht R, Schwander T, Keller L: Genetic components to

- caste allocation in a multiple-queen ant species. Evolution 2011, 65:2907-2922.

A rare example of successful controlled crosses with ant colonies.

6. Schwander T, Lo N, Beekman M, Oldroyd B, Keller L: Nature versus nurture in social insect caste differentiation. Trends Ecol Evol 2010, 25:275-357.

7. Oster G, Wilson E: Caste and ecology in the social insects. Monogr Popul Biol 1978, 12:1-353.

8. Robinson GE: Regulation of honey bee age polyethism by juvenile hormone. Behav Ecol Sociobiol 1987, 20:329-338.

9. Bortolotti L, Duchateau MJ, Sbrenna G: Effect of juvenile hormone on caste determination and colony processes in the bumblebee Bombus terrestris. Entomol Exp Appl 2001 101:143-158.

10. Passera L, Suzzoni JP: Sexualisation du couvain de la fourmi Pheidole pallidula (Hymenoptera, formicidae) apres traitement par l'hormone juvenile. C R Hebd Seances Ser D Sci Nat 1978, 268.

11. Rajakumar R, San Mauro D, Dijkstra M, Huang M, Wheeler D, Hiou- Tim F, Khila A, Cournoyea M, Abouheif E: Ancestral developmental potential facilitates parallel evolution in ants. Science 2012, 335:79-161.

The use of in situ gene expression analysis and hormonal treatments to better understand the evolution of the morphological differentiaton controlled by juvenile hormone.

12. Wheeler D: Developmental and physiological determinants of caste in social Hymenoptera: evolutionary implications. Am Nat 1986, 128:13-34.

13. Wheeler $\mathrm{D}$, Nijhout $\mathrm{H}$ : Soldier determination in ants: new role for juvenile hormone. Science 1981, 213:361-364.

14. Dolezal A, Brent C, Hölldobler B, Amdam G: Worker division of labor and endocrine physiology are associated in the harvester ant, Pogonomyrmex californicus. J Exp Biol 2012, 215:454-514.

15. Huang Z, Robinson G: Honeybee colony integration: workerworker interactions mediate hormonally regulated plasticity in division of labor. Proc Natl Acad Sci US A 1992, 89:11726-11735.

16. Robinson G: Effects of a juvenile hormone analogue on honey bee foraging behaviour and alarm pheromone production. $J$ Insect Physiol 1985, 31:277-282.

17. Robinson GE: Regulation of honey-bee age polyethism by juvenile-hormone. Behav Ecol Sociobiol 1987, 20:329-338.

18. Faber T, Joerges J, Menzel R: Associative learning modifies neural representations of odors in the insect brain. Nat Neurosci 1999, 2:74-82.

19. Galizia C, Joerges J, Küttner A, Faber T, Menzel R: A semi-in vivo preparation for optical recording of the insect brain. $J$ Neurosci Methods 1997, 76:61-70.

20. Galizia CG, Rossler W: Parallel olfactory systems in insects: anatomy and function. Annu Rev Entomol 2010, 55:399-420. 
21. Brandstaetter A, Rössler W, Kleineidam C: Friends and foes from an ant brain's point of view - neuronal correlates of colony odors in a social insect. PLOS ONE 2011:6.

22. Hoyer SC, Liebig J, Rössler W: Biogenic amines in the ponerine ant Harpegnathos saltator: serotonin and dopamine immunoreactivity in the brain. Arthropod Struct Devel 2005 34:429-869.

23. Kelber C, Rössler W, Kleineidam C: Phenotypic plasticity in number of glomeruli and sensory innervation of the antennal lobe in leaf-cutting ant workers (A. vollenweideri). Dev Neurobiol 2010, 70:222-256.

24. Kuebler L, Kelber C, Kleineidam C: Distinct antennal lobe phenotypes in the leaf-cutting ant (Atta vollenweideri). J Comp Neurol 2010, 518:352-417.

25. Mizunami M, Yamagata N, Nishino $\mathrm{H}$ : Alarm pheromone processing in the ant brain: an evolutionary perspective. Front Behav Neurosci 2010, 4:28.

26. Nakanishi A, Nishino $H$, Watanabe $H$, Yokohari F, Nishikawa M: Sex-specific antennal sensory system in the ant Camponotus japonicus: structure and distribution of sensilla on the flagellum. Cell Tissue Res 2009, 338:79-176.

27. Nishikawa M, Watanabe H, Yokohari F: Higher brain centers for social tasks in worker ants, Camponotus japonicus. J Comp Neurol 2012, 520:1584-1682.

28. Zube C, Kleineidam C, Kirschner S, Neef J, Rössler W: Organization of the olfactory pathway and odor processing in the antennal lobe of the ant Camponotus floridanus. J Comp Neurol 2008, 506:425-466.

29. Groh C, Rossler W: Caste-specific postembryonic development of primary and secondary olfactory centers in the female honeybee brain. Arthropod Struct Dev 2008, 37:459-468.

30. Bonasio R, Zhang G, Ye C, Mutti N, Fang X, Qin N, Donahue G, Yang P, Li Q, Li C et al.: Genomic comparison of the ants Camponotus floridanus and Harpegnathos saltator. Science 2010, 329:1068-1139.

31. Gadau Jr, Helmkampf M, Nygaard S, Roux J, Simola D, Smith C, Suen G, Wurm Y, Smith C: The genomic impact of 100 million years of social evolution in seven ant species. Trends Genet $2012,28: 14-35$.

32. Honeybee genome sequencing $\mathrm{C}$ : insights into social insects from the genome of the honeybee Apis mellifera. Nature 2006, 443:931-980.

33. Nygaard S, Zhang G, Schiott M, Li C, Wurm Y, Hu H, Zhou J, Ji L, Qiu F, Rasmussen M et al:: The genome of the leaf-cutting ant Acromyrmex echinatior suggests key adaptations to advanced social life and fungus farming. Genome Res 2011, 8:1339-2687.

34. Smith C, Smith C, Robertson H, Helmkampf M, Zimin A, Yandell M, Holt $\mathrm{C}$, Hu H, Abouheif $\mathrm{E}$, Benton Ret al.: Draft genome of the red harvester ant Pogonomyrmex barbatus. Proc Natl Acad Sci U S A 2011, 108:5667-5739.

35. Smith $C$, Zimin A, Holt $C$, Abouheif $E$, Benton $R$, Cash $E$ Croset V, Currie C, Elhaik E, Elsik $C$ et al.: Draft genome of the globally widespread and invasive Argentine ant (Linepithema humile). Proc Natl Acad Sci U S A 2011, 108:5673-5681.

36. Stolle E, Wilfert L, Schmid-Hempel R, Schmid-Hempel P, Kube M, Reinhardt R, Moritz R: A second generation genetic map of the bumblebee Bombus terrestris (Linnaeus, 1758) reveals slow genome and chromosome evolution in the Apidae. BMC Genomics 2011, 12:48.

37. Suen G, Teiling C, Li L, Holt C, Abouheif E, Bornberg-Bauer E, Bouffard P, Caldera E, Cash E, Cavanaugh A et al.: The genome sequence of the leaf-cutter ant Atta cephalotes reveals insights into its obligate symbiotic lifestyle. PLoS Genet 2011:7.

38. Werren J, Richards S, Desjardins C, Niehuis O, Gadau Jr, Colbourne J, Nasonia Genome Working G, Beukeboom L, Desplan C, Elsik C et al.: Functional and evolutionary insights from the genomes of three parasitoid Nasonia species. Science 2010, 327:343-351.
39. Munoz-Torres MC, Reese JT, Childers CP, Bennett AK, Sundaram JP, Childs KL, Anzola JM, Milshina N, Elsik CG: Hymenoptera Genome Database: integrated community resources for insect species of the order Hymenoptera. NuCl Acids Res 2011, 39:D658-D662.

40. Whitfield C, Cziko A-M, Robinson G: Gene expression profiles in the brain predict behavior in individual honey bees. Science 2003, 302:296-305.

41. Liang Z, Nguyen $T$, Mattila $H$, Rodriguez-Zas $S$, Seeley $T$, Robinson G: Molecular determinants of scouting behavior in honey bees. Science 2012, 335:1225-1233.

42. Chandrasekaran S, Ament S, Eddy J, Rodriguez-Zas S, Schatz B,

- Price N, Robinson G: Behavior-specific changes in transcriptional modules lead to distinct and predictable neurogenomic states. Proc Natl Acad Sci U S A 2011 , 108:18020-18025.

A large-scale microarray study of honeybee brain gene expression, which reveals transcriptional networks that correlate with behavioral maturation.

43. Ament S, Wang $\mathrm{Y}$, Chen $\mathrm{C}-\mathrm{C}$, Blatti C, Hong F, Liang Z, Negre N, White K, Rodriguez-Zas S, Mizzen C et al.: The transcription factor ultraspiracle influences honey bee social behavior and behavior-related gene expression. PLOS Genet 2012:8.

44. Alaux C, Le Conte Y, Adams H, Rodriguez-Zas S, Grozinger C, Sinha S, Robinson G: Regulation of brain gene expression in honey bees by brood pheromone. Genes Brain Behav 2009, 8:309-328.

45. Alaux C, Sinha S, Hasadsri L, Hunt GJ, Guzman-Novoa E, DeGrandi-Hoffman G, Uribe-Rubio JL, Southey BR, RodriguezZas S, Robinson GE: Honey bee aggression supports a link between gene regulation and behavioral evolution. Proc Natl Acad Sci U S A 2009, 106:15400-15405.

46. Steller MM, Kambhampati S, Caragea D: Comparative analysis of expressed sequence tags from three castes and two life stages of the termite Reticulitermes flavipes. BMC Genomics 2010, 11:463.

47. Wang Y, Brent C, Fennern E, Amdam G: Gustatory perception and

- fat body energy metabolism are jointly affected by vitellogenin and juvenile hormone in honey bees. PLoS Genet 2012:8.

This paper is one of the first examples bridging physiology, gene expression and behavioral assays.

48. Wang Y, Mutti NS, Ihle KE, Siegel A, Dolezal AG, Kaftanoglu O, Amdam GV: Down-regulation of honey bee IRS gene biases behavior toward food rich in protein. PLOS Genet 2010, 6:e1000896.

49. Ament SA, Wang $Y$, Robinson GE: Nutritional regulation of division of labor in honey bees: toward a systems biology perspective. Syst Biol Med 2010, 2:566-576.

50. Gulia-Nuss M, Robertson AE, Brown MR, Strand MR: Insulin-like peptides and the target of rapamycin pathway coordinately regulate blood digestion and egg maturation in the mosquito Aedes aegypti. PLOS ONE 2011, 6:e20401.

51. Richard DS, Rybczynski $R$, Wilson TG, Wang $Y$, Wayne ML, Zhou Y, Partridge L, Harshman LG: Insulin signaling is necessary for vitellogenesis in Drosophila melanogaster independent of the roles of juvenile hormone and ecdysteroids: female sterility of the chico1 insulin signaling mutation is autonomous to the ovary. J Insect Physiol 2005, 51:455-464.

52. Amdam GV, Csondes A, Fondrk MK, Page RE Jr: Complex social behaviour derived from maternal reproductive traits. Nature 2006, 439:76-78.

53. Weiner SA, Toth AL: Epigenetics in social insects: a new direction for understanding the evolution of castes. Genet Res Int 2012, 2012:609810.

54. Zhang TY, Meaney MJ: Epigenetics and the environmenta regulation of the genome and its function. Annu Rev Psychol 2010, 61:439-466 C431-C433.

55. Lyko F, Foret S, Kucharski R, Wolf S, Falckenhayn C, Maleszka R: The honey bee epigenomes: differential methylation of brain DNA in queens and workers. PLOS Biol 2010:8. 
56. Bonasio R, Li Q, Lian J, Mutti NS, Jin L, Zhao H, Zhang P, Wen P, Xiang $\mathrm{H}$, Ding $\mathrm{Y}$ et al.: Genome-wide and caste-specific DNA methylomes of the ants Camponotus floridanus and Harpegnathos saltator. Curr Biol 2012.

57. Smith CR, Mutti NS, Jasper WC, Naidu A, Smith CD, Gadau J: Patterns of DNA methylation in development, division of labor and hybridization in an ant with genetic caste determination. PLOS ONE 2012, 7:e42433.

58. Jassim O, Huang Z, Robinson G: Juvenile hormone profiles of worker honey bees, Apis mellifera, during normal and accelerated behavioural development. J Insect Physiol 2000, 46:243-492.

59. Staal GB: Anti juvenile-hormone agents. Annu Rev Entomol 1986, 31:391-429.

60. Sigg D, Thompson CM, Mercer AR: Activity-dependent changes to the brain and behavior of the honey bee, Apis mellifera (L.). $J$ Neurosci 1997, 17:7148-7156.

61. Tibbetts $E$, Sheehan $M$ : The effect of juvenile hormone on

- Polistes wasp fertility varies with cooperative behavior. Horm Behav 2012, 61:559-623.

The use of primitively eusocial wasps in this study reveals parallels in the role of juvenile hormone in solitary and social insects.

62. Matsuura K, Himuro C, Yokoi T, Yamamoto Y, Vargo E, Keller L:

- Identification of a pheromone regulating caste differentiation in termites. Proc Natl Acad Sci U S A 2010 107:12963-12971.

An elegant example of pheromone discovery and function.

63. Yamamoto Y, Matsuura K: Queen pheromone regulates egg production in a termite. Biol Lett 2011, 7:727-736.

64. Wanner K, Nichols A, Walden K, Brockmann A, Luetje C, Robertson $\mathrm{H}$ : A honey bee odorant receptor for the queen substance 9-oxo-2-decenoic acid. Proc Natl Acad Sci U S A 2007, 104:14383-14391.

65. Nunes F, Simões Z: A non-invasive method for silencing gene transcription in honeybees maintained under natural conditions. Insect Biochem Mol Biol 2009, 39:157-217.

66. Zhou X, Wheeler M, Oi F, Scharf M: RNA interference in the termite Reticulitermes flavipes through ingestion of doublestranded RNA. Insect Biochem Mol Biol 2008, 38:805-820.

67. Bellés X: Beyond Drosophila: RNAi in vivo and functional genomics in insects. Annu Rev Entomol 2010, 55:111-139.

68. Hunt J, Mutti N, Havukainen H, Henshaw M, Amdam G: Development of an RNA interference tool, characterization of its target, and an ecological test of caste differentiation in the eusocial wasp polistes. PLOS ONE 2011:6.

69. Gempe T, Hasselmann M, Schiott M, Hause G, Otte M, Beye M: Sex determination in honeybees: two separate mechanisms induce and maintain the female pathway. PLOS Biol 2009:7.

70. Mackert A, do Nascimento A, Bitondi M, Hartfelder K, Simões Z: Identification of a juvenile hormone esterase-like gene in the honey bee, Apis mellifera L. - expression analysis and functional assays. Comp Biochem Physiol Part B Biochem Mol Biol 2008, 150:33-77.

71. Nelson C, Ihle K, Fondrk M, Page R, Amdam G: The gene vitellogenin has multiple coordinating effects on social organization. PLoS Biol 2007:5.

72. Lynch J, Desplan C: A method for parental RNA interference in the wasp Nasonia vitripennis. Nat Protoc 2006, 1:486-580.

73. Choi MY, Vander Meer RK, Coy M, Scharf ME: Phenotypic impacts of PBAN RNA interference in an ant, Solenopsis invicta, and a moth, Helicoverpa zea. J Insect Physiol 2012 58:1159-1165.

74. Korb J, Weil T, Hoffmann K, Foster K, Rehli M: A gene necessary -. for reproductive suppression in termites. Science 2009, 324:758.

A powerful application of molecular techniques, including RNAi, in a notyet-sequenced social insect, which identifies a molecular cue that affects reproductive division of labor.
75. Zhou X, Oi F, Scharf M: Social exploitation of hexamerin: RNAi reveals a major caste-regulatory factor in termites. Proc Natl Acad Sci U S A 2006, 103:4499-5003.

76. Bendesky A, Bargmann C: Genetic contributions to behavioural diversity at the gene-environment interface. Nat Rev Genet 2011, 12:809-829.

77. Kamakura M: Royalactin induces queen differentiation in •• honeybees. Nature 2011, 473:478-561.

A pioneering study revealing an important mechanism of honeybee queen specification through a nutritional signal (royalactin) by use of Drosophila melanogaster as a heterologous, genetically accessible experimental system.

78. Bibikova M, Golic M, Golic K, Carroll D: Targeted chromosomal cleavage and mutagenesis in Drosophila using zinc-finger nucleases. Genetics 2002, 161:1169-1244.

79. Wood A, Lo T-W, Zeitler B, Pickle C, Ralston E, Lee A, Amora R, Miller J, Leung E, Meng X et al.: Targeted genome editing across species using ZFNs and TALENs. Science 2011, 333:307.

80. Ando T, Fujiyuki T, Kawashima T, Morioka M, Kubo T, Fujiwara H: In vivo gene transfer into the honeybee using a nucleopolyhedrovirus vector. Biochem Biophys Res Commun 2007, 352:335-340.

81. Hamilton AR, Boyce F, Neve RL, Robinson GE: Methods for the in vivo and in vitro transduction of adult honey bee neurons. Society for Neuroscience. USA: New Orleans, LA; 2012.

82. Ross K, Keller L: Genetic control of social organization in an ant. Proc Natl Acad Sci U S A 1998, 95:14232-14239.

83. Wang J, Ross K, Keller L: Genome-wide expression patterns and the genetic architecture of a fundamental social trait. PLoS Genet 2008:4.

84. de Belle J, Hilliker A, Sokolowski M: Genetic localization of foraging (for): a major gene for larval behavior in Drosophila melanogaster. Genetics 1989, 123:157-220.

85. de Bono $\mathrm{M}$, Bargmann $\mathrm{C}$ : Natural variation in a neuropeptide $\mathbf{Y}$ receptor homolog modifies social behavior and food response in C. elegans. Cell 1998, 94:679-768.

86. Branson K, Robie AA, Bender J, Perona P, Dickinson M: Highthroughput ethomics in large groups of Drosophila. Nat Methods 2009, 6:451-457.

87. Robinson E, Smith F, Sullivan K, Franks N: Do ants make direct comparisons? Proc Biol Sci/Roy Soc 2009, 276:2635-2676.

88. Sumner S, Lucas E, Barker J, Isaac N: Radio-tagging technology reveals extreme nest-drifting behavior in a eusocial insect. Curr Biol 2007, 17:140-145.

89. Zube C, Rössler W: Caste- and sex-specific adaptations within the olfactory pathway in the brain of the ant Camponotus floridanus. Arthropod Struct Dev 2008, 37:469-548.

90. Lu HL, Pietrantonio PV: Immunolocalization of the short neuropeptide $F$ receptor in queen brains and ovaries of the red imported fire ant (Solenopsis invicta Buren). BMC Neurosci 2011, 12:57.

91. Riveros AJ, Seid MA, Wcislo WT: Evolution of brain size in classbased societies of fungus-growing ants (Attini). Anim Behav 2012, 83:1043-1049.

92. Brandt R, Rohlfing T, Rybak J, Krofczik S, Maye A, Westerhoff M, Hege HC, Menzel R: Three-dimensional average-shape atlas of the honeybee brain and its applications. J Comp Neurol 2005, 492:1-19.

93. Smid HM, Bleeker MA, van Loon JJ, Vet LE: Three-dimensional organization of the glomeruli in the antennal lobe of the parasitoid wasps Cotesia glomerata and C. rubecula. Cell Tissue Res 2003, 312:237-248.

94. Zhou X, Slone JD, Rokas A, Berger SL, Liebig J, Ray A, Reinberg D, Zwiebel LJ: Phylogenetic and Transcriptomic Analysis of Chemosensory Receptors in a Pair of Divergent Ant Species Reveals Sex-Specific Signatures of Odor Coding. PLOS Gen 2012, 8:e1002930. 